\title{
Monensina para Bezerros Ruminantes em Crescimento Acelerado. 2. Digestibilidade e Parâmetros Ruminais
}

\author{
Márcia Saladini Vieira Salles ${ }^{1}$, Carlos de Sousa Lucci² $^{2}$
}

\begin{abstract}
RESUMO - Os efeitos da suplementação de monensina nos parâmetros ruminais e na digestibilidade foram analisados após 120 dias de experimentação, utilizando-se 20 bezerros inteiros holandeses com peso e idade médios de 90,8 kg e 80 dias, respectivamente. Os tratamentos foram: $0 ; 0,4 ; 0,8 ; \mathrm{e} 1,2 \mathrm{mg}$ de monensina/kg PV. Com o aumento dos níveis de monensina, os valores ruminais de $\mathrm{pH}$ (5,97; 6,$14 ; 6,36$; e 6,48) elevaram-se e os de $\mathrm{N}-\mathrm{NH}_{3}(45,54 ; 38,08 ; 28,39 ;$ e $24,17 \mathrm{mg} \%)$, ácido acético $(36,55 ; 33,72 ; 35,62 ;$ e 26,35 mM) e ácido butírico $(10,22 ; 7,27 ; 6,13 ;$ e 4,30 mM) e a quantidade total de ácidos graxos voláteis $(79,07 ; 72,91 ; 73,44 ;$ e 58,57 mM) diminuíram no rúmen. A monensina proporcionou aumento dos coeficientes de digestibilidade aparente (CDEB com 50,51; 53,59; 55,89; e 60,43\%; CDMS com 59,34; 60,47; 62,37; e 66,38\%; CDPB com 73,56; 75,07; 75,92; e 78,31\%; CDFDN com 30,64; 31,92; 35,84; e 43,72\%; e CDFDA com 13,$16 ; 17,25 ; 22,55 ;$ e $31,21 \%$ para $0 ; 0,4 ; 0,8 ;$ e 1,2 respectivamente) e da porcentagem de nutrientes digestíveis (NDT com 59,12; 60,57; 61,91; e 65,52\%; ED com 1776,07; 1884,38; 1965,24; e 2124,79 cal/g; MSD com 59,34; 60,47; 62,37; e 66,38\%; PD com 14,$35 ; 14,64 ; 14,81$; e $15,27 \%$; e FDND com 10,$65 ; 11,10 ; 12,46$; e $15,20 \%$ para $0 ; 0,4 ; 0,8$; e 1,2 respectivamente). A monensina teve efeito positivo sobre os parâmetros ruminais estudados, melhorando a digestibilidade do alimento.
\end{abstract}

Palavras-chave: bezerros, ionóforos, pH, amônia, ácidos graxos voláteis, nutrientes digestíveis

\section{Monensin for Ruminant Calves in Fast Rate Growth. 2. Digestibility and Ruminal Parameters}

\begin{abstract}
The effects of the monensin supplementation on the ruminal parameters and digestibility were evaluated after 120 days of trial, using 20 Holstein bull calves with average weight and age of $90.8 \mathrm{~kg}$ and 80 days, respectively. The treatments were 0 , $.4, .8$ and $1.2 \mathrm{mg}$ of monensin $/ \mathrm{kg} \mathrm{LW}$. As the monensin levels increased the $\mathrm{pH}$ values increased $(5.97,6.14,6.36$, and 6.48$)$, but $\mathrm{N}-\mathrm{NH}_{3}$ $(45.54,38.08,28.39$, and $24.17 \mathrm{mg} \%)$, acetate $(36.55,33.72,35.62$, and $26.35 \mathrm{mM})$, butyrate $(1.22,7.27,6.13$, and $4.30 \mathrm{mM})$ and total volatile fatty acids $(79.07,72 ., 91,73.44,58.57 \mathrm{mM})$ decreased in the rumen. The monensin increased the coefficient of apparent digestibility (GEDC with 50.51, 53.59, 55.89, and 60.43\%; DMDC with 59.34, 60.47, 62.37, and 66.38\%; CPDC with 73.56, 75.07, 75.92, and 78.31\%; NDFDC with 30.64, 31.92, 35.84, and 43.72\%; ADFDC with 13.16, 17.25, 22.55, and 31.21\% for $0,0.4,0.8$, and 1.2, respectively) and of the TDN (NDT with 59.12, 60.57, 61.91, and 65.52\%; ED with 1776,07; 1884.38, 1965.24, and 2124.79 cal/g; MSD with 59.34, 60.47, 62.37, and 66.38\%; PD with 14.35, 14.64, 14.81, and 15.27\%; DNDF with 10.65, 11.10, 12.46, and 15.20\% for $0,0.4,0.8$, and 1.2 , respectively). Monensin positively influenced the studied ruminal parameters, improving the feed digestibility.
\end{abstract}

Key Words: ammonia, calves, digestible nutrients, ionophores, $\mathrm{pH}$, volatile fatty acid

\section{Introdução}

A monensina, um ionóforo produzido por uma cepa de Streptomyces cinnamonensis, pertencente à classe geral de compostos denominados poliéteres (Haney JR. e Hoehn, 1968, citados por HADDAD e LOURENÇO JR., 1977), altera a fermentação no rúmen, modificando as proporções dos ácidos graxos voláteis, aumentando a concentração de ácido propiônico e diminuindo de ácido acético (NATIONAL RESEARCH COUNCIL - NRC,1989).
Os estudos realizados com monensina têm registrado modificações na ingestão alimentar, na digestibilidade, na produção de gases, na produção de ácidos graxos, na utilização da proteína e no enchimento e na taxa de passagem pelo rúmen. Este ionóforo tem sido o principal produto utilizado como aditivo alimentar para bovinos, entre mais de setenta ionóforos conhecidos (SCHELLING, 1984). Pesquisas revelaram seus efeitos na fermentação ruminal, em que a produção de gás metano é reduzida em cerca de $30 \%$, tornando maior a energia do alimento

\footnotetext{
${ }^{1}$ Doutoranda FCF/USP.E.mail:saladini@usp.br.

2 Prof. Dr. UNISA. E.mail: cslucci@sti.com.br

3 Instituições Financiadoras: Fapesp e Elanco.
} 
disponível para produção (RUSSEL e STROBEL, 1989). Os melhores desempenhos obtidos com o emprego do ionóforo são atribuídos principalmente à maior eficiência do metabolismo energético e nitrogenado no rúmen, ocorrendo ainda diminuição de distúrbios metabólicos, como acidose lática e timpanismo.

Dados de uma revisão realizada por GOODRICH et al. (1984) sugerem que a monensina aumenta a digestibilidade da matéria seca, reduz a produção de calor em jejum e aumenta os valores de energia líquida da dieta para mantença.

Os coeficientes de digestibilidade aparente da proteína foram elevados linearmente pelo incremento das concentrações do ionóforo lasalocida (de 0 a 30 $\mathrm{mg} / \mathrm{kg}$ de concentrado), porém as digestibilidades da MS em vacas lactantes (DYE et al., 1988) não foram afetadas. Em estudo realizado por GALLOWAY et al. (1993) com novilhos holandeses alimentados com uma dieta volumosa de baixa qualidade, suplementada com monensina, ocorreu aumento das digestibilidades da matéria orgânica e da FDN. Contudo, quando as rações foram suplementadas com milho, não foram encontradas diferenças na ingestão ou digestão, sugerindo efeitos diferentes do ionóforo na dependência da qualidade da ração fornecida.

THORNTON e OWENS (1981) utilizaram dietas com baixa (12,6\% PB e $12 \%$ FDA), média (12,3\% PB e $27 \%$ FDA) e alta proporção de forragem $(14,4 \%$ PB e 40\% FDA) com e sem $200 \mathrm{mg}$ de monensina suplementar. Com a suplementação, a produção de metano decresceu $16 \%$ para os níveis menores e $24 \%$ para o mais alto; a energia metabolizável aumentou $5,2 \%$ em todos os níveis em que foram utilizados o aditivo; e a digestibilidade da matéria seca e retenção de $\mathrm{N}$ não foram alteradas, embora tendessem a aumentar com a adição de monensina.

Quando os animais são submetidos a dietas com excesso de proteína degradável no rúmen, grande quantidade de amônia se acumula neste órgão. Nesta situação, com a adição de monensina, houve redução de $30 \%$ de amônia e os aminoácidos poupados da desaminação puderam ser utilizados por outras bactérias, aumentando a concentração de proteína microbiana no fluido ruminal (YANG e RUSSEL, 1993b).

O objetivo deste trabalho foi estudar os efeitos da monensina sobre os parâmetros ruminais de AGV, $\mathrm{N}-\mathrm{NH}_{3}$ e pHe a digestibilidade do alimento fornecido a bezerros da raça Holandesa em crescimento, em sistema de confinamento.

\section{Material e Métodos}

O experimento foi realizado na Faculdade de Medicina Veterinária e Zootecnia da Universidade de São Paulo, Campus Administrativo de Pirassununga, em posição geográfica de $21^{\circ} 59^{\prime}$ de latitude Sul e $47^{\circ} 26^{\prime}$ de longitude Oeste, à altitude de 634 metros. A pesquisa foi desenvolvida no interior do estábulo leiteiro, onde os animais permaneceram contidos individualmente, cada qual com acesso ao cocho de ração e de água. O experimento teve duração de 120 dias, realizado nos período de junho a outubro de 1996. Foram utilizados 20 bezerros da raça Holandesa, machos recém nascidos oriundos de uma mesma fazenda, e iniciado o período experimental com 80 dias de idade e peso médio de $90,8 \pm 0,5 \mathrm{~kg}$.

O delineamento estatístico utilizado foi em blocos casualizados (GOMES, 1985), com quatro tratamentos e cinco blocos, sendo os blocos formados conforme o peso dos bezerros.

Os tratamentos estudados foram: 1) controle, sem monensina; 2) 0,4 mg de monensina/kg de PV; 3) 0,8 mg de monensina $/ \mathrm{kg}$ de PV; e 4) $1,2 \mathrm{mg}$ de monensina $/ \mathrm{kg}$ de PV. Foram determinadas a digestibilidade da ração, as concentrações de AGVs, pH e as concentrações de nitrogênio amoniacal no rúmen.

A fonte de monensina utilizada foi o produto comercial Rumensin (Eli Lilly do Brasil- Divisão Elanco Saúde Animal) com $100 \mathrm{~g}$ de monensina ativa $/ \mathrm{kg}$ do produto. Houve um período de uma semana de adaptação dos animais à mistura que continha monensina, sendo o ionóforo aumentado gradualmente.

A ração foi ministrada na forma peletizada, fornecida duas vezes ao dia, à vontade (7h30 e 14 h), sendo retiradas e pesadas as sobras diariamente na manhã do dia seguinte, para controle do consumo individual diário. Na presença de até $100 \mathrm{~g}$ de sobra de ração, aumentavam-se $250 \mathrm{~g}$ no total diário.

A monensina foi fornecida duas vezes ao dia, sempre antes das refeições, sendo pesada em balança analítica e ministrada em mistura com $80 \mathrm{~g}$ de fubá e $20 \mathrm{~g}$ de leite em pó; este último ingrediente foi utilizado como palatabilizante, totalizando $100 \mathrm{~g}$ de veículo. Logo após os bezerros terem ingerido a monensina, a ração previamente pesada em balança eletrônica era colocada no cocho, repetindo-se o mesmo processo no período da tarde. Os animais do grupo controle receberam o mesmo veículo, sem monensina. Amostras de ração foram coletadas mensalmente e analisadas conforme normas da ASSOCIATION OF OFFICIAL ANALYTICAL 
584 Rev. bras. zootec.

CHEMISTS - AOAC (1990). A composição e os resultados da análise bromatológica da ração fornecida encontram-se na Tabela 1, em porcentagem, sendo a matéria seca obtida a $105^{\circ} \mathrm{C}$.

Após as pesagens, as doses de monensina foram ajustadas semanalmente, conforme as médias de peso dos blocos. Os bezerros foram inspecionados todos os dias quanto ao estado de saúde e, quando necessário, medicados. Alterações e medicamentos utilizados foram registrados.

Ao atingir 100 dias de experimentação, foi realizado um ensaio de digestibilidade com emprego de marcador (óxido crômio) em todos os animais. $\mathrm{O}$ óxido crômio foi ministrado para os bezerros em cápsulas de gelatina, tendo cada bezerro recebido $6 \mathrm{~g}$ do marcador diariamente, divididos em duas aplicações, durante 10 dias, injetadas diretamente no esôfago com aplicador tipo pistola. A partir do quinto dia, as fezes foram coletadas individualmente em sacos plásticos, quatro horas depois da administração do óxido crômio, colocadas em bandejas de alumínio e secas em estufa a $65^{\circ} \mathrm{C}$, por 72 horas. Após, foram moídas em moinho equipado com peneira de $1 \mathrm{~mm}$, homogeneizadas e guardadas em congelador a $-20^{\circ} \mathrm{C}$ até o momento da análise. A determinação do óxido crômio nas fezes foi feita pelo método colorimétrico da s-difenilcarbazida (GRANER, 1972; GRANER et al., 1992). O NDT foi obtido somando a proteína digestível (\%), juntamente com a fibra bruta digestível (\%), o extrativo não-nitrogenado digestível (\%) e o extrato etéreo digestível (\%) multiplicado por 2,25.

Depois do abate, assim que obtido o líquido ruminal, o mesmo foi homogeneizado, coletando-se amostras para determinar AGV, pH e N-NH . Foram colocados $5 \mathrm{~mL}$ de líquido ruminal dentro de um tubo de centrífuga, adicionando-se $1 \mathrm{~mL}$ de ácido metafosfórico (25\%) e centrifugado por 10 minutos em centrífuga de $3000 \mathrm{rpm}$. O sobrenadante foi analisado em um cromatógrafo a gás com detector de ionização de chama, segundo proposição de ERWIN et al. (1961), para AGVs medidos em concentração molar (mM). $\mathrm{O}$ pH foi medido logo após a retirada das amostras do líquido ruminal, por intermédio de um potenciômetro digital (marca Corning modelo PS-30), calibrado com soluções tampão de pH 4,0 e 7,0. As amostras para determinação do nitrogênio amoniacal $\left(\mathrm{NH}_{3}-\mathrm{N}\right)$ do líquido ruminal foram feitas em duplicata, por intermédio do método de colorimetria, segundo proposição de KULASEK (1972) e adaptado por FOLDAGER (1977).

Os resultados foram analisados por intermédio do programa computacional Statistical Analysis System (SAS Institute Inc., 1985). As variâncias e as normalidades dos resíduos foram testadas previamente, utilizando-se o teste F para análise de variância e o teste de SHAPIRO-WILK para a normalidade dos resíduos (PROC UNIVARIATE).

Os dados que não apresentaram normalidade de seus resíduos foram submetidos à transformação $\log$ arítmica $(\log X+1)$ ou raiz quadrada $[R Q(X+1 / 2)]$, para posterior análise de variância pelo procedimento GLM (PROC GLM). Os resultados que apresentaram homogeneidade das variâncias e normalidade de resíduo foram submetidos ao teste de regressão (PROC GLM), por intermédio de contrastes, obtendo-se as equações das retas (PROC REG). O nível de significância de $5 \%$ foi adotado para todos os testes realizados.

\section{Resultados e Discussão}

Foi encontrada regressão linear $(\mathrm{P}<0,05)$ para os coeficientes de digestibilidade aparente, bem como para NDT, ED, MSD, PD e FDND, em que os valores se elevaram com o aumento dos níveis de monensina. Os coeficientes de digestibilidade apa-

Tabela 1 - Composição percentual e teores de matéria seca (MS), matéria mineral (MM) extrato etéreo (EE), fibra em detergente neutro (FDN), proteína bruta (PB), Ca e $P$ da ração experimental

Table 1 - Percentage composition and contents of dry matter (DM), mineral matter (MM), ether extract (EE), neutral detergent fiber (NDF), crude protein (CP), Ca and $P$ of the experimental diet

\begin{tabular}{|c|c|c|c|c|c|c|}
\hline $\begin{array}{c}\text { Feno de } \\
\text { coast-cross } \\
\text { Coast-cross } \\
\text { hay }\end{array}$ & $\begin{array}{l}\text { Farelo de } \\
\text { soja } \\
\text { Soybean } \\
\text { meal }\end{array}$ & $\begin{array}{l}\text { Fubá de } \\
\text { milho } \\
\text { Corn meal }\end{array}$ & $\begin{array}{l}\text { Farinha de } \\
\text { trigo } \\
\text { Wheat meal }\end{array}$ & $\begin{array}{c}\text { Supl. } \\
\text { mineral } \\
\text { Mineral } \\
\text { supplement }\end{array}$ & Caulin & Total \\
\hline 30,0 & 20,0 & 32,0 & 12,5 & 1,5 & 4,0 & 100 \\
\hline MS & MM & $\mathrm{EE}$ & FDN & PB & $\mathrm{Ca}$ & $\mathrm{P}$ \\
\hline$D M$ & & & $N D F$ & $C P$ & & \\
\hline 90,97 & 8,63 & 2,3 & 31,53 & 17,74 & 0,60 & 0,47 \\
\hline
\end{tabular}


rente encontram-se na Tabela 2 e os valores de nutrientes digestíveis, na Tabela 3.

Os ensaios em que se estudaram os efeitos da monensina sobre a digestibilidade dos alimentos têm produzido resultados bastantes variáveis. A duração dos experimentos, o aporte de nutrientes das dietas (incluindo o nível de proteína verdadeira) e as proporções concentrados:volumosos são fatores que influenciam estes resultados. Contudo, na maioria dos ensaios, a monensina causou aumento na digestibilidade (SCHELLING, 1984; MEDEL et al., 1991) da MS e FDN, em novilhos canulados no rúmen e no duodeno (FAULKNER et al., 1985), da MS e EB em novilhos alimentados com dieta pobre em proteína
(BEEDE et al., 1986) e da MS, PB e FB, em dietas altas e baixas em fibras, em novilhos Holandeses (ARAUJO-FEBRES e FERNÁNDEZ, 1991). Houve também aumento na digestibilidade da MS e EB, em novilhos alimentados com dietas concentradas e adaptados com monensina (Beede et al., 1980, citados por SCHELLING, 1984). Por outro lado, THORNTON e OWENS (1981), DARDEN et al. (1985) e GALLOWAY et al. (1993) não encontraram influência da monensina sobre a digestibilidade e POOS et al. (1979) registraram diminuição na digestibilidade da MS com suplementação do ionóforo.

SPEARS (1990), em sua revisão, observou que o ionóforo utilizado em bovinos aumenta a energia

Tabela 2 - Coeficientes de digestibilidade aparente, em porcentagem, da energia bruta (CDEB), matéria seca (CDMS), proteína bruta (CDPB), fibra em detergente neutro digestível (CDFDN) e fibra detergente ácido (CDFDA), em função dos níveis de monensina na dieta (M)

Table 2 - Coefficients of apparent digestibility (\%) of the gross energy (CDGE), dry matter (CDDM), crude protein (CDCP), digestible neutral detergent fiber (CDNDF) and acid detergent fiber (CDADF), in function of monensin levels in the diet (M)

\begin{tabular}{|c|c|c|c|c|c|c|c|}
\hline \multirow[t]{2}{*}{ Item } & \multicolumn{4}{|c|}{$\begin{array}{l}\mathrm{mg} \text { de monensina } / \mathrm{kg} \text { de } \mathrm{PV} \\
m g \text { of the monensin/ } \mathrm{kg} L W\end{array}$} & \multirow[b]{2}{*}{$\mathrm{CV}$} & \multirow{2}{*}{$\begin{array}{c}\text { Probabilidade } \\
\text { Probability } \\
\text { Linear }\end{array}$} & \multirow[t]{2}{*}{$\begin{array}{l}\text { Regressão } \\
\text { Regression }\end{array}$} \\
\hline & 0 & 0,4 & 0,8 & 1,2 & & & \\
\hline $\begin{array}{l}\text { CDEB } \\
C D G E\end{array}$ & 50,51 & 53,59 & 55,89 & 60,43 & 12,45 & 0,0186 & $\mathrm{~EB}=50,29+8,05 \mathrm{M}$ \\
\hline $\begin{array}{l}\text { CDMS } \\
C D D M\end{array}$ & 59,34 & 60,47 & 62,37 & 66,38 & 8,62 & 0,0299 & $\mathrm{MS}=58,69+5,75 \mathrm{M}$ \\
\hline $\begin{array}{l}\text { CDPB } \\
C D C P\end{array}$ & 73,56 & 75,07 & 75,92 & 78,31 & 4,82 & 0,0470 & $\mathrm{~PB}=73,44+3,77 \mathrm{M}$ \\
\hline $\begin{array}{l}\text { CDFDN } \\
C D N D F\end{array}$ & 30,64 & 31,92 & 35,84 & 43,72 & 28,97 & 0,0350 & $\mathrm{FDN}=29,06+10,7 \mathrm{M}$ \\
\hline $\begin{array}{l}\text { CDFDA } \\
C D A D F \\
\end{array}$ & 13,16 & 17,25 & 22,55 & 31,21 & 62,85 & 0,0184 & $\mathrm{FDA}=12,12+14,8 \mathrm{M}$ \\
\hline
\end{tabular}

Tabela 3 - Nutrientes digestíveis totais (NDT), energia digestível (ED), matéria seca digestível (MSD), proteína digestível (DP) e fibra em detergente neutro digestível (FDND) na dieta de bezerros, em função dos diferentes níveis de monensina (M)

Table 3 - Total digestible nutrients (TDN), digestible energy (DE), digestible dry matter (DDM), digestible crude protein $(D C P)$ and digestible neutral detergent fiber (DNDF) in calves diets, in function of the different monensin levels (M)

\begin{tabular}{|c|c|c|c|c|c|c|c|}
\hline \multirow[t]{2}{*}{ Item } & \multicolumn{4}{|c|}{$\begin{array}{l}\mathrm{mg} \text { de monensina } / \mathrm{kg} \text { de PV } \\
m g \text { of the monensin } / \mathrm{kg} \mathrm{LW}\end{array}$} & \multirow[b]{2}{*}{$\mathrm{CV}$} & \multirow{2}{*}{$\begin{array}{c}\text { Probabilidade } \\
\text { Probability } \\
\text { Linear } \\
\end{array}$} & \multirow[t]{2}{*}{$\begin{array}{l}\text { Regressão } \\
\text { Regression }\end{array}$} \\
\hline & 0 & 0,4 & 0,8 & 1,2 & & & \\
\hline $\begin{array}{l}\text { NDT }(\%) \\
T D N\end{array}$ & 59,12 & 60,57 & 61,91 & 65,52 & 7,69 & 0,0308 & $\mathrm{NDT}=58,70+5,1 \mathrm{M}$ \\
\hline $\begin{array}{l}\mathrm{ED}(\mathrm{cal} / \mathrm{g}) \\
D E\end{array}$ & 1776,07 & 1884,38 & 1965,24 & 2124,79 & 12,45 & 0,0187 & $\mathrm{ED}=1768,56+281,75 \mathrm{M}$ \\
\hline $\begin{array}{l}\operatorname{MSD}(\%) \\
D D M\end{array}$ & 59,34 & 60,47 & 62,37 & 66,38 & 8,62 & 0,0299 & $\mathrm{MSD}=58,69+5,75 \mathrm{M}$ \\
\hline $\begin{array}{l}\mathrm{PD}(\%) \\
D C P\end{array}$ & 14,35 & 14,64 & 14,81 & 15,27 & 4,82 & 0,0471 & $\mathrm{PD}=14,33+0,73 \mathrm{M}$ \\
\hline $\begin{array}{l}\text { FDND }(\%) \\
D N D F\end{array}$ & 10,65 & 11,10 & 12,46 & 15,20 & 28,96 & 0,0351 & $\mathrm{FDND}=10,10+3,74 \mathrm{M}$ \\
\hline
\end{tabular}


digestível em média de $2 \%$. Neste experimento, a suplementação do ionóforo aumentou os nutrientes digestíveis totais em 2,$4 ; 4,7$; e 10,8\%; energia digestível, em 6,$0 ; 10,6 ;$ e 19,6\%; e a proteína digestível em 2,0;3,2; e 6,4\%, para os tratamentos 0,$4 ; 0,8 ;$ e 1,2, respectivamente, comparados com o controle.

Os resultados referentes aos parâmetros de fermentação ruminal encontram-se nas Tabelas 4 e 5 . Para o líquido ruminal coletado depois do abate, foi encontrado efeito linear para a concentração de ácido acético, ácido butírico e quantidade de ácidos graxos totais, os quais foram reduzidos com o aumento dos níveis de monensina. Numerosos estudos têm demonstrado troca na proporção molar de ácidos graxos voláteis no rúmen. Esta troca apresenta aumento do propiônico e diminuição das proporções de acetato e butirato, e a concentração total de AGV se mantém estável ou sofre pequena diminuição, sendo conseqüência da troca na ecologia microbiana do rúmen (MEDEL et al., 1991). Foram encontrados, neste trabalho, resultados apenas para a diminuição do ácido acético e butírico, sendo que para o propiônico não foi obtida resposta significativa. SHELL et al. (1983), trabalhando com novilhos alimentados em dieta com alta quantidade de grãos, obtiveram aumento do propiônico nos animais suplementados com monensina. Os resultados obtidos no líquido ruminal foram equivalentes aos encontrados na literatura (HADDAD e LOURENÇO JR., 1977; HOLZER et al., 1979; TURNER et al., 1980; BOIN et al., 1984; e ZINN e BORQUES, 1993). Já DUFF et al. (1995) encontraram aumento na concentração molar de acético, propiônico e AGV total, com diminuição do butirato e da proporção acético/propiônico, em virtude da fermentação in vitro de uma dieta com $90 \%$ de concentrado.

Os valores de $\mathrm{pH}$ no material ruminal apresentaram aumento linear significativo $(\mathrm{p}<0,05)$ com o

Tabela 4 - Ácidos graxos voláteis (mM) nas amostras de líquido ruminal coletado após abate dos animais, em função dos diferentes níveis de monensina na dieta (M)

Table 4 - Volatile fatty acids (mM) in the samples of rumen fluid collected just after slaughter of the animals, in function of the different monensin levels in the diet $(M)$

\begin{tabular}{|c|c|c|c|c|c|c|c|}
\hline \multirow[t]{2}{*}{ Item } & \multicolumn{4}{|c|}{$\begin{array}{c}\mathrm{mg} \text { de monensina } / \mathrm{kg} \text { de } \mathrm{PV} \\
m g \text { of the monensin/kg LW }\end{array}$} & \multirow[b]{2}{*}{$\mathrm{CV}$} & \multirow{2}{*}{$\begin{array}{c}\text { Probabilidade } \\
\text { Probability } \\
\text { Linear } \\
\end{array}$} & \multirow[t]{2}{*}{$\begin{array}{l}\text { Regressão } \\
\text { Regression }\end{array}$} \\
\hline & 0 & 0,4 & 0,8 & 1,2 & & & \\
\hline $\begin{array}{l}\text { Ácido acético } \\
\text { Acetic acid }\end{array}$ & 36,55 & 33,72 & 35,62 & 26,35 & 20,44 & 0,0410 & $\mathrm{AA}=35,75+4,89 \mathrm{M}$ \\
\hline $\begin{array}{l}\text { Ácido propiônico } \\
\text { Propionic acid }\end{array}$ & 30,19 & 31,90 & 31,68 & 27,91 & 17,54 & 0,5473 & \\
\hline $\begin{array}{l}\text { Ácido butírico } \\
\text { Butyric acid } \\
\text { Ác. acético/ }\end{array}$ & 10,22 & 7,27 & 6,13 & 4,30 & 38,55 & 0,0007 & $\mathrm{AP}=10,02-6,60 \mathrm{M}$ \\
\hline $\begin{array}{l}\text { Ác. propiônico } \\
\text { Acetic acid/ } \\
\text { propionic acid }\end{array}$ & 1,21 & 1,07 & 1,13 & 0,95 & 16,08 & 0,0609 & \\
\hline $\begin{array}{l}\text { AGV total } \\
\text { Total volatile } \\
\text { fatty acid }\end{array}$ & 79,07 & 72,91 & 73,44 & 58,57 & 17,93 & 0,0238 & $\mathrm{AGV}=77,97+1,07 \mathrm{M}$ \\
\hline
\end{tabular}

Tabela 5 - Valores médios de $\mathrm{pH}$ e $\mathrm{N}-\mathrm{NH}_{3}$ (mg\%) em amostras de líquido ruminal coletado após abate dos animais, em função dos diferentes níveis de monensina na dieta (M)

Table 5 - Average values of $\mathrm{pH}$ and $\mathrm{NH}_{3}(\mathrm{mg} \%)$ in rumen fluid samples collected just after animals slaughter, in function of the different monensin levels in the diet $(M)$

\begin{tabular}{|c|c|c|c|c|c|c|c|}
\hline \multirow[t]{2}{*}{ Item } & \multicolumn{4}{|c|}{$\begin{array}{l}\mathrm{mg} \text { de monensina } / \mathrm{kg} \text { de } \mathrm{PV} \\
m g \text { of the monensin/ } \mathrm{kg} L W\end{array}$} & \multirow[b]{2}{*}{$\mathrm{CV}$} & \multirow{2}{*}{$\begin{array}{c}\text { Probabilidade } \\
\text { Probability } \\
\text { Linear }\end{array}$} & \multirow[t]{2}{*}{$\begin{array}{l}\text { Regressão } \\
\text { Regression }\end{array}$} \\
\hline & 0 & 0,4 & 0,8 & 1,2 & & & \\
\hline$\overline{\mathrm{pH}}$ & 5,974 & 6,146 & 6,366 & 6,486 & 4,236 & 0,0006 & $\mathrm{pH}=5,979+0,439 \mathrm{M}$ \\
\hline $\mathrm{N}-\mathrm{NH}_{3}$ & 45,54 & 38,08 & 28,39 & 24,17 & 28,21 & 0,0001 & $\mathrm{~N}-\mathrm{NH}_{3}=45,11-18,59 \mathrm{M}$ \\
\hline
\end{tabular}


emprego de níveis mais elevados de monensina. $\mathrm{Na}$ literatura, o ionóforo produziu aumento significativo no $\mathrm{pH}$ ruminal in vitro (SCHELLING, 1984); benefícios similares foram encontrados por NAGARAJA et al. (1982), HORN et al. (1981), SHELL et al. (1983), BRANINE e GALYEAN (1990) e CLARY et al. (1993). Contudo, vários autores não encontraram resultados significativos de alteração do $\mathrm{pH}$ ruminal com a suplementação do ionóforo (DINIUS et al., 1976; POOS et al., 1979; HOLZER et al., 1979; NAGARAJA et al., 1982; DARDEN et al., 1985; BEACON et al., 1988; YANG e RUSSELL, 1993a; e ZINN e BORQUES, 1993).

Ruminantes alimentados com dietas ricas em concentrados tendem a apresentar diminuição do $\mathrm{pH}$ do conteúdo ruminal, podendo ocorrer acidose, porém os animais suplementados com monensina apresentam aumento do pH ruminal (RUSSEL e STROBEL, 1989). Entretanto, DUFF et al. (1995), trabalhando com dieta contendo $90 \%$ de concentrados, não encontraram diferenças no $\mathrm{pH}$ ruminal com a utilização de ionóforo. $\mathrm{O}$ pH encontrado na presente situação foi sempre superior a 6,0 nos tratamentos com ionóforo.

Os resultados do $\mathrm{N}-\mathrm{NH}_{3}$ apresentaram regressão linear $(\mathrm{p}<0,05)$, diminuindo a concentração com o aumento dos níveis de monensina. Foram obtidos valores relativamente altos de $\mathrm{N}-\mathrm{NH}_{3}$ para todos os animais, que se encontravam em jejum por 12 horas. No abate, houve tempo médio de 30 minutos da morte do animal até a coleta do líquido ruminal; tempo suficiente para contínua produção de $\mathrm{N}-\mathrm{NH}_{3}$ no rúmen, sem absorção.

DARDEN et al. (1985) e CLARY et al. (1993), também trabalhando com dietas concentradas, não encontraram diferenças nos valores de $\mathrm{NH}_{3}$ com a suplementação de monensina.

HANSON e KLOPFENSTEIN (1979), trabalhando com bovinos em crescimento; BRANINE e GALYEAN (1990), com novilhos; e YANG e RUSSEL (1993 a), com vacas não lactantes, encontraram diminuição do $\mathrm{N}-\mathrm{NH}_{3}$ nos tratamentos com monensina em relação aos tratamentos controle. Segundo esses autores e MEDEL et al. (1991), a diminuição da produção de $\mathrm{N}-\mathrm{NH}_{3}$ ruminal pode ter sido causada indiretamente por depressão no número total de células bacterianas, reduzindo assim a proteólise. A suplementação com monensina pode aumentar a fração proteína dietética que escapa à degradação ruminal e seria utilizada nos intestinos.

\section{Conclusões}

A adição de monensina melhorou as condições ruminais, em alimentação com maior quantidade de concentrado, proporcionando aumento na digestibilidade do alimento, resultando em maior quantidade de nutrientes a ser aproveitado pelo animal, para melhor condição de desenvolvimento.

Os melhores resultados foram obtidos com o nível de $1,8 \mathrm{mg}$ de monensina/kg de PV.

\section{Agradecimento}

À FAPESP e à empresa Elanco, pelo apoio financeiro.

\section{Referências Bibliográficas}

ASSOCIATION OF OFFICIAL ANALYTICAL CHEMISTS AOAC. 1990. Official methods of analysis. 15.ed. Washington: AOAC. 1298p.

ARAUJO-FEBRES, O., FERNÁNDEZ, M.D.C. 1991. Effecto en novillos del monensin y el nivel de fibra de la dieta sobre el consumo y la digestibilidad de la materia seca. Rev. Fac. Agr., 8:143-153.

BEACOM, S.E., MIR, Z., KORSRUD, G.O. et al. 1988. Effect of the additives chlortetracycline, monensin and lasalocid on feedlot performance of finishing cattle, liver lesions and tissue levels of chlortetracycline. Can. J. Sci., 68:1131-1141.

BEEDE, D.K., SCHELLING, G.T., MITCHELL, G.E. et al. 1986. Nitrogen utilization and digestibility by growing steers and goats of diets that contain monensin and low crude protein. J. Anim. Sci., 62:857-863.

BOIN, C., LEME, P.R., NARDON, R.F. et al. 1984. A monensina sódica no ganho de peso e na conversão alimentar de zebuínos em confinamento. Zootecnia, 22(3):247-255.

BRANINE, M.E., GALYEAN, M.L. 1990. Influence of grain and monensin supplementation on ruminal fermentation, intake, digesta kinetics and incidence and severity of frothy bloat in steers grazing winter wheat pasture. J. Anim. Sci., 68:1139-1150.

CLARY, E.M., BRAND JR., R.T., HARMON, D.L. et al. 1993. Supplemental fat and ionophores in finishing diets: feedlot performance and ruminal digesta kinetics in steers. J. Anim. Sci., 71:3115-3123.

DARDEN, D.E., MERCHEN, N.R., BERGER, L.L. et al. 1985. Effects of avoparcin, lasalocid and monensin on sites of nutrient digestion in beef steers. Nutrition Reports International. 31(4):979-989.

DINIUS, D.A., SIMPSON, M.E., MARSH, P.B. 1976. Effect of monensin fed with forage on digestion and the ruminal ecosystem of steers. J. Anim. Sci., 42(1):229-234.

DUFF, G.C., GALYEAN, M.L., BRANINE, M.E. 1995. Effects of lasalocid and monensim plus tylosin on serum metabolic hormones and clinical chemistry profiles of beef steers fed a 90\% concentrate diet. J. Anim. Sci., 72(4):1049-1058.

DYE, B.E., AMOS, H.E., FROETSCHEL, M.A. 1988. Influence of lasalocid on rumen metabolites, milk production, milk composition and digestibility in lactating cows. Nutrition 
588 Rev. bras. zootec.

Reports International, 38(1):101-115.

ERWIN, E.S., MARCO, G.J., EMERI, E.M. 1961. Volatile fatty acid analyses of blood and rumen fluid by gas chromatography. J. Dairy Sci., 44(9):1768-1771.

FAULKNER, D.B., KLOPFENSTEIN, T.J., TROTTER, T.N. et al. 1985. Monensin effects on digestibility, ruminal protein escape and microbial protein synthesis on high-fiber diets. J. Anim. Sci., 61(3):654-660.

FOLDAGER, J. Protein requeriment and non- protein nitrogen for high producing cow in early lactation. East Lasing. Ph.D. Thesis. Michigan State University, 1977. 142p.

GALLOWAY, D.L., GOETSCH, A.L., PATIL, A. et al. 1993. Feed intake and digestion by Holstein steer calves consuming low-quality grass supplemented with lasalocid or monensin. Can. J. Anim. Sci., 73:869-879.

GOMES, P.F. 1985. Curso de estatística experimental. Piracicaba, SP: ESALQ. 467p.

GOODRICH, R.D., GARRETT, J.E., GAST, D.R. et al. 1984. Influence of monensin on the performance of cattle. J. Anim. Sci., 58(6):1484-1498.

GRANER, C.A.F. Determinação do crômio pelo método colorimétrico da s-difenilcarbazida. Botucatu. 1972. 112p. Tese (Doutorado) - Faculdade de Ciências Médicas e Biológicas.

GRANER, C.A.F., LOPES, A.M., COSTA, P.C. et al. 1992. Determinação colorimétrica do crômio quando utilizado como marcador biológico na forma de óxido de crômio (III). 14p. (Projeto de pesquisa contemplado com auxílio da FUNDUNESP, proc. 196/92-DFP/F/CET).

HADDAD, C.M., LOURENÇO JR., J.B. 1977. Monensina: um novo aditivo na alimentação de ruminantes. Zootecnia, 15(3):171-181.

HANSON, T.L., KLOPFENSTEIN T. 1979. Monensin, protein source and protein levels for growing steers. J. Anim. Sci., 48(3):474-479.

HOLZER, Z., ILAN, D., LEVY, D. 1979. A note on the effects of monensin on the performance and on rumen metabolites of intact male cattle. Anim. Prod., 28:135-137.

HORN, G.W., MADER, T.L., ARMBRUSTER, S.L. et al. 1981. Effect of monensin on ruminal fermentation, forage intake and weight gains of wheat pasture stocker cattle. J. Anim. Sci., 52(3):447-454.

KULASEK, G.A. 1972. A micromethod for determination of urea in plasma, whole blood and blood cells using urease and phenolreagent. Pol. Arch. Wet., 15(4):801-810.

MEDEL, M., MERINO, P., THOMAS, R. et al. 1991. Modo de acción del monensin en metabolismo ruminal y comportamiento animal. Ciencia e investigación Agraria., 18(3):153-173.

NAGARAJA, T.G., AVEY, T.B., BARTLEY, E.E. 1982. Effect of lasalocid, monensin or thiopectin on lactic acidosis in cattle. J. Anim. Sci., 54(3):649-658.
NATIONAL RESEARCH COUNCIL - NRC. 1989. Nutrient requirements of dairy cattle. 6.ed.rev.atual. Washington. $61 \mathrm{p}$.

POOS, M.I., HANSON, T.L., KLOPFENSTEIN, T.J. 1979. Monensin effects on diet digestibility, ruminal protein bypass and protein synthesis. J. Anim. Sci., 48(6):1516-1524.

RUSSEL, J.B., STROBEL, H.J. 1989. Effect of ionophores on ruminal fermentation. Applied and Environmental Microbiology, 55(1):1-6.

SAS Institute SAS User's guide: statistics. 5.ed., Cary, NC. 1985. 252p.

SCHELLING, G.T. 1984. Monensin mode of action in the rumen. J. Anim. Sci., 58(6):1518-1527.

SHELL, L.A., HALE, W.H., THEURER, B. et al. 1983. Effect of monensin on total volatile fatty acid production by steers fed a high grain diet. J. Anim. Sci., 57(1):178-185.

SPEARS, J.W. Ionophores and nutrient digestion and absorption in ruminants. In: SYMPOSIUM GUT METABOLISM AND NUTRIENT SUPPLY, Raleigh, North Carolina State University, 1990. Proceedings...Raleigh, p.632-37, 1990.

THORNTON, J.H., OWENS, F.N. 1981. Monensin supplementation and in vivo methane production by steers. J. Anim. Sci., 52(3):628-634.

TURNER, H.A., YOUNG, D.C., RALEIGH, R.J. et al. 1980. Effect of various levels of monensin on efficiency and production of beef cows. J. Anim. Sci., 50(3):385-390.

YANG, Che-Ming J., RUSSEL, J.B. 1993a. The effect of monensin supplementation on ruminal ammonia accumulation in vivo and the numbers of amino acid-fermenting bacteria. J. Anim. Sci., 71(12):3470-3476.

YANG, Che-Ming J., RUSSEL, J.B. 1993b. The effect of monensin on the flow of amino nitrogen from the rumen. J.Dairy Sci., 76:179. (suppl.1)

ZINN, R.A., BORQUES, J.L. 1993. Influence of sodium bicarbonate and monensin on utilization of a fatsupplemented, hight-energy growing-finishing diet by feedlot steers. J. Anim. Sci., 71:18-25.

Recebido em: 01/02/99

Aceito em: 13/09/99 